\title{
A Guiding Design System for Pressure Vessels based on 3D CAD
}

\author{
http://dx.doi.org/10.3991/ijoe.v12i05.5721 \\ Shanhui Zhang ${ }^{1}$, Chaoying Yang $^{2}$, Ning $\mathrm{Xu}^{2}$ \\ ${ }^{1}$ Shandong University, Jinan, China \\ 2 Shandong Shanda Hoteam Soft Co., Ltd, Jinan, China
}

\begin{abstract}
The design of pressure vessel is an extremely professional job which has heavy workload, repeated work, and rich accumulated knowledge, and it has good characteristics of serialization, generalization, standardization. Generic 3D CAD systems are not suitable for pressure vessel design. On the contrary, customized development based on 3D CAD system is needed. In this paper, a new pressure vessel design system based on Chinese 3D CAD system named SINOVATION was developed to improve design efficiency and accuracy. First, the functions and construction of pressure vessel design system were presented with the analysis of the traditional design process of pressure vessels. Second, related design specifications were managed and used flexibly in pressure vessel design system, and general parts library and standard parts library were established to improve parts reuse and accumulation. Finally, a guiding design mode was accepted for typical vessels and components to design same product series while direct modeling function was used for atypical pressure vessels. The results show that this method is helpful for embedded use of design specifications, standards and knowledge, and also provides an extensive interface for product updates and diversification. Statistical data reports and accurate engineering drawings are generated automatically based on 3D models. The quality, efficiency, and consistence are greatly improved. With the implementation and application, the system has been highly commended by customers in Chinese pressure vessel industry, especially in petrochemical industry.
\end{abstract}

Index Terms - pressure vessel, design guide, standard parts library, three-dimensional modeling

\section{INTRODUCTION}

Pressure vessels are used for many industrial processes, for example in petrochemical plants, off-shore oil rigs, and gas storage and control systems. In each case pressure vessels must be carefully designed to cope with the operating temperatures and pressures [1-2]. The size and geometric form of pressure vessels vary greatly from the large cylindrical vessels used for high-pressure gas storage to the small size used as hydraulic units for aircraft [3]. The design of pressure vessels has become vitally important for engineers to meet the increasing service demands, quality requirements and safety legislation. In pressure vessel design process, engineers need to understand the fundamental principles underlying the methodologies of dozens or even hundreds of design standards codes. Pressure vessels need strict calculations and analysis, lots of engineering drawings, several kinds of statistical data. So the design of pressure vessel is an extremely professional job which has heavy workload, repeated work, and rich accumulated knowledge [4]. At present, CAD tools are becoming increasingly powerful, and they provide users with more efficiency and improve the overall performance of design activities [5]. Because of the professional and special of pressure vessel design, all the generic 3D CAD systems are not good choices for pressure vessel design. As pressure vessels also have good characteristics of serialization, generalization, and standardization, pressure vessel design is very suitable for customized development of 3D CAD system.

There are several professional 3D design systems for pressure vessels already existing in the world. Because of their high cost of purchasing and maintenance, poor customization, different design ideas and national standards, they can't meet the requirements of Chinese domestic enterprises. As a result, the majority of Chinese pressure vessel design and manufacturing enterprises are still using 2D CAD systems, which seriously restrict enterprise design efficiency and capability of independent innovation, and lead to lots of problems, such as enterprise data inconsistent and poor ability of collaborative design.

Therefore, a pressure vessel design system based on Chinese 3D CAD system named SINOVATION is researched on and developed to solve problems above. In this paper, an overview of the traditional design process of pressure vessels is presented in order to analyze the corresponding requirements. Then the functions and construction of pressure vessel design system is proposed. At last, the system is developed and applied in several petrochemical enterprises.

\section{Description Of The Problem}

The traditional design process of pressure vessels mainly includes several stages which are analysis of design conditions, proposal of design scheme, review of design scheme, detailed design, design check and review. Therein, the detailed design is the design stage with largest workload and most complex task, which directly affected the entire product design efficiency. So it will have a positive impact on pressure vessel design quality and efficiency with work reduces in the detailed design stage.

The detailed design stage includes vessel calculation and analysis, generation of finished files, and overall analysis and output. The design process is shown in Figure 1. As can be seen from the figure, detailed design of pressure vessel involves a lot of calculation, analysis and drawing work, produces design calculations, 2D drawings and related statistical data, and also needs to establish 3D models for product simulation and analysis [6-7]. In the 
traditional design process, 2D drawings are separated from 3D models, which lead to repetitive design work and design defects. So pressure vessel design system based on 3D CAD should solve problems above occurred in traditional design processes.

\section{STATE Of THE ART}

As pressure vessel design is a professional and special work, only a few scholars study the design system of pressure vessels. Sato T., Nomoto T., Kado K., et al [8] established a new user-friendly structural design system for pressure vessels which is based on finite element stress analyses, and fundamental performances of the system are demonstrated through the analysis of a top nozzle. H. J. Aziz [9] developed a simple, time saving, user-friendly and in-house software to support design system for pressure vessel design using MatLab r2009a. Zhu M. S., Long W., and Yin L. I. [10] developed an integrated system of parameterized design and defects assessment of pressure vessels based on software of Visual Basic 6.0 and ANSYS The key technology of the system is design of the APDL (ANSYS Parametric Design Language) templates and method of the establishing of finite model of pressure vessels containing defects. Using parameterized design technique and VBA tools, Yun N. I., Zheng Y. P., and Sheng J. S. [11] developed Pressure Vessels CAD system based on AutoCAD. The system realized the automatic design process from data to drawing, and it has a friendly interface and runs smoothly. I. J. S. Attwater, J. Anderson, G. E. Findlay [12] researched on a knowledge based system for the design of pressure vessel, and combined disparate software to form an integrated pressure vessel design system. Song Y. D. [13] made a modern design system for pressure vessels, judge failure reasons rapidly and table proposals. As mentioned, most of the design systems separate pressure vessel design process with CAD system, or use $2 \mathrm{D} \mathrm{CAD}$. This does not conform to the trend of $3 \mathrm{D}$ design in nowadays. So a pressure vessel design system based on $3 \mathrm{D}$ CAD system is required for pressure vessel industry.

\section{Methodology}

\section{A. System Structure}

According to the functional requirements described above, a pressure vessel design system is presented, and its structure is shown in Figure 2. The system is divided into six functional layers which are basic core layer of SINOVATION, general function layer of SINOVATION, data maintenance layer, system data layer, system command layer and industrial application layer.

(1) Basic core layer of SINOVATION: It mainly plays a supporting role for CAD system, and manages the corresponding memory use, graphics display, interaction with operating systems and system log. It also manages various function libraries for modeling, drawing and assembly, as well as associated graphics display, database management and development, etc. The basic core layer is the basis to achieve the upper functions, and is also the kernel part of CAD system.

(2) General function layer of SINOVATION: Provides various general functions, such as 3D modeling, engineering drawings, assembly modeling, guided design, data

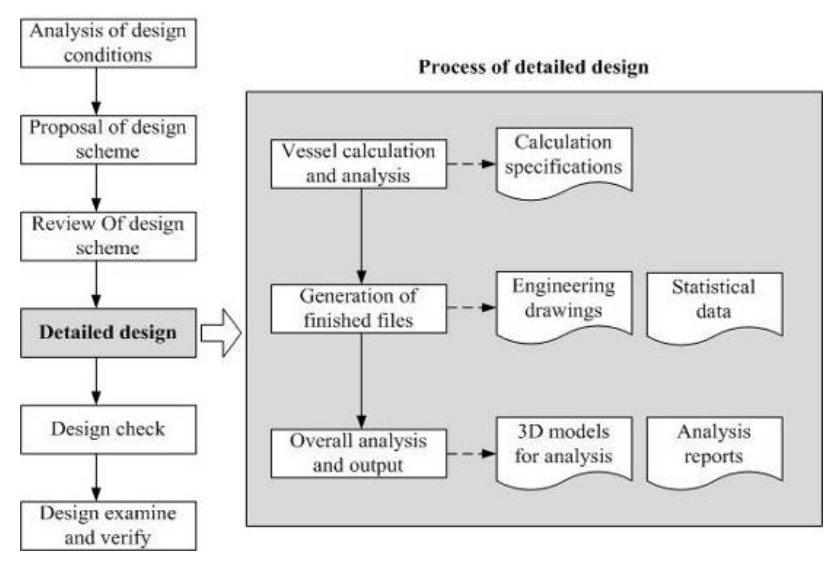

Figure 1. Design process of pressure vessels

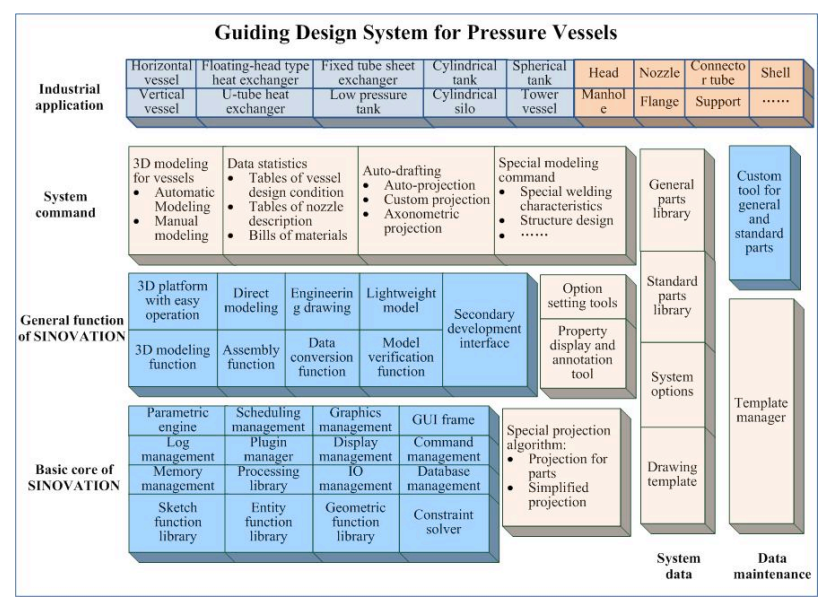

Figure 2. The structure of pressure vessel design system

exchange and more, which covers basic function modules for product design and manufacturing.

(3) Data maintenance layer: Provides tools for standard parts customization, template generation and management in order to maintain data consistency with customer needs.

(4) System data layer: This layer is used to save system background data, including various types of general parts, standard parts and drawing templates.

(5) System command layer: According to the characteristics of pressure vessels, provides specialized tools for 3D modeling, data statistics, auto-drafting, and special modeling.

(6) Industrial application layer: Through the combination of the above five layers, a specialized design system for pressure vessels is formed to support calculation, modeling, product file generation, analysis and output work for several types of pressure vessels and components.

\section{B. System functions}

With the analysis of product characteristics and design processes of pressure vessels, the pressure vessel design system provides the following functions.

\section{(1) Design pressure vessel with 3D CAD}

3D models contain product information more than 2D drawings, and have the characteristic of intuitive design [14]. It is easier to find the problems in product design and avoid errors transfer to the drawings, manufacturing, assembly, or other stages. In addition, 3D CAD system can finish calculation work for physical and geometrical prop- 
erties of every part or component, and also can do mechanical analysis avoid remodeling. Therefore, design with $3 \mathrm{D}$ CAD is an inevitable developing trend of product design methods. Some 3D part models with annotations are shown in Figure 3. brary

(2) Establish general parts library and standard parts li-

The structure and shape of pressure vessel parts are uniformed into several kinds of specifications, and parts are always used interchangeably in the same specification. General parts library and standard parts library are needed. Figure 4 shows several general parts which are frequently reused in pressure vessel design. In order to adapt to industry development, the library should be customizable [15].

(3) Manage and flexibly use standards and specifications

In pressure vessel design, various types of standards and specifications must be referred to [16-18]. So industry design standards, manuals and special formulas should be embedded in product design process to avoid devastating accidents and improve product design efficiency and quality.

(4) Provide flexible plotting capabilities

For pressure vessels, engineering drawings should express not only the product structure, shape, size, and performance, but also manufacturing, installation and other technical requirements. Therefore, according to different vessel types, national standards and industry specifications, pressure vessel design system should support user defined 2D plotting rules and provide related engineering drawings based on 3D models with the construction requirements of pressure vessels.

(5) Apply design guide in typical pressure vessel design

The design methods and design processes of some typical pressure vessels are relatively standardized, and have accumulated a wealth of knowledge and engineering checking rules [19]. So it is perfectly appropriate to use design guide for typical pressure vessels, and it is a good way to integrate design rules and knowledge into 3D CAD.

(6) Support atypical pressure vessel design with direct modeling

In addition to typical pressure vessels, roughly $20 \%$ of pressure vessels are atypical pressure vessels, which are not suitable for design guide technology [19]. In order to improve the design efficiency of atypical pressure vessels, direct modeling based on general modeling function is essential to model rapidly by modifying similar 3D models.

(7) Develop professional design and assembly module

By analyzing the composition, structure and assembly of pressure vessels, it can be found that the part species is relatively fixed, the structure are serial and standardized, and they always assembled with certain rules and regulations. Therefore, professional design and assembly module for pressure vessels should be developed to provide efficient modeling and assembly tools based on various structural features. In the pressure vessel design system, three location methods are provided for product design or assembly, which are rectangular coordinate method, cylindrical coordinate method and spherical coordinate method. Most parts can be designed and positioned with these methods (shown in Figure 5).

\section{RESUlt ANALysis AND Discussion}

Following the above function and structure design, a pressure vessel design system is developed, and it can be used in enterprise preliminary design, detailed design, and manufacturing and maintenance phases. The corresponding process is shown in Figure 6.

In preliminary design stage, the system can only use about 10 minutes to rapidly establish a pressure vessel model making use of the guiding design mode. Moreover, it can automatically statistics related parts and materials for cost estimate, which is greatly helpful in submitting a project tender.
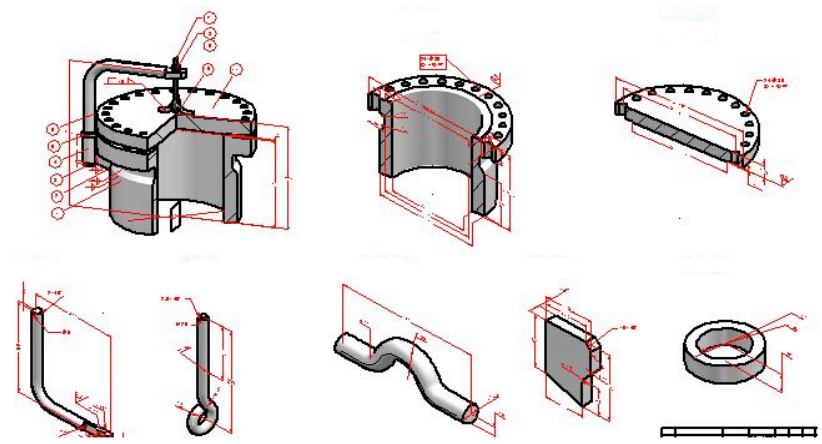

Figure 3. 3D models with three-dimensional annotations

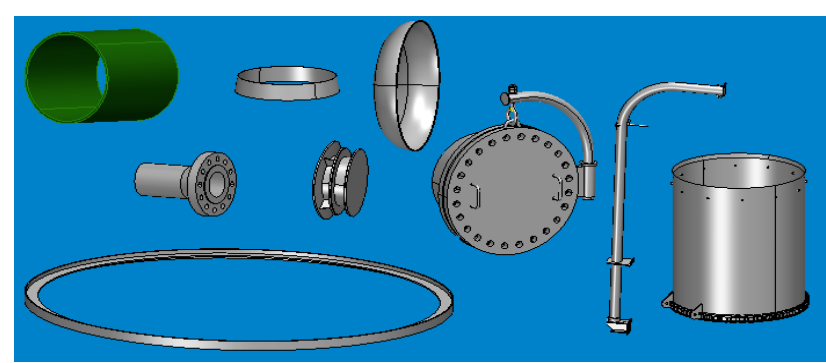

Figure 4. Examples of parts library
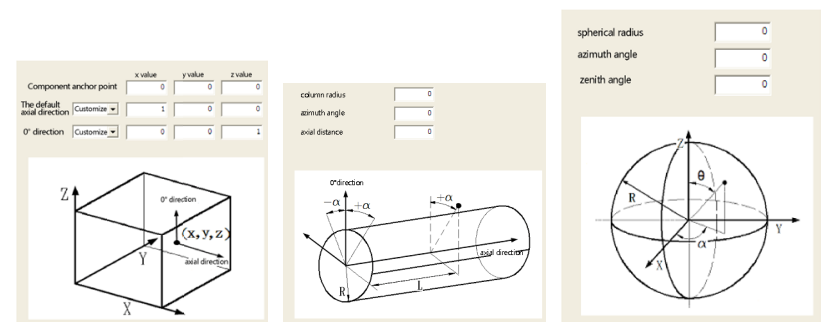

Figure 5. Location methods based on three different coordinate systems. (a) Rectangular Coordinate, (b) Cylindrical Coordinate, (c) Spherical Coordinate

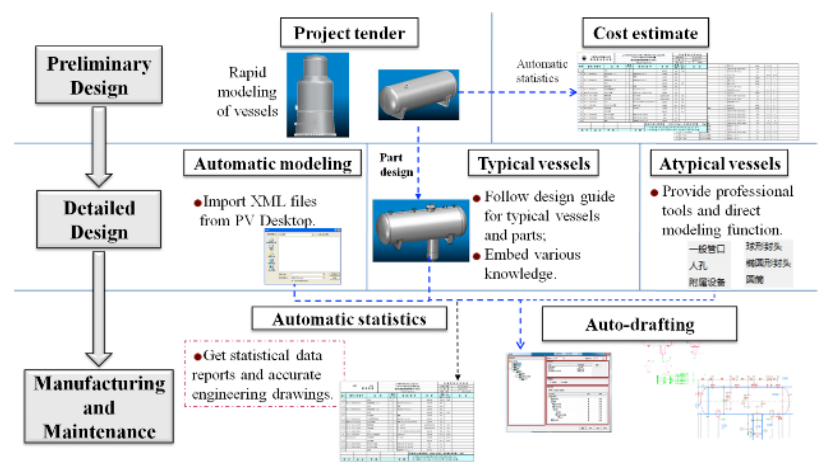

Figure 6. The work process of pressure vessel design system 
In detailed design stage, it can import XML files from PV Desktop and build product 3D models automatically according to information from files analysis. For typical pressure vessels, based on 3D models from preliminary design or XML files analysis, the system can add or adjust part detail structure following customer requirements, or some kinds of standards and calculation analysis, then finish the detailed design of this typical vessel. For atypical pressure vessels, the system can provide professional tools and direct modeling function to support rapid design.

In manufacturing and maintenance stage, on the basis of detailed design, users can get statistical data reports and accurate engineering drawings used for vessel manufacturing, project construction and post-maintenance etc.

In the pressure vessel design system, design guide is an important guarantee to improve design efficiency and quality. Taking a simple horizontal pressure vessel design as an example in Figure7, completion of model A requires at least four steps from B to E.

Step 1 is rapid modeling with design guide. In this step, select "horizontal pressure vessel" design template (shown in Figure 8), start design guide for horizontal pressure vessel, and complete related information of 10 tabs which consist of design specifications, design conditions, vessel structures, earthquake load, wind load, medium parameters, insulation, lining layer, mixed soil and design options. Through above operations, model B in Figure 7 can be rapidly completed.

Steps 2 to 4 are modeling for basic components. Users should select water drum, liquid level gauge and manhole, then finish design and modeling for related components following the design guide. Taking manhole for example, select manhole command and start manhole design guide. Later, complete 5 tabs which are design condition, nozzle parameters, structure parameters, connecting format and design options, shown in Figure 9. At last, model E can be accomplished.

There is a rapid engineering drawing while the whole pressure vessel model is accomplished. Various types of construction drawings can be rapidly completed by choosing drawing template of horizontal pressure vessel.

In addition, the guiding design system for pressure vessels provides a $3 \mathrm{D}$ viewer to browse online lightweight models with mobile devices anywhere conveniently in construction or maintenance stage, shown in Figure 10. This method can significantly improve the design, construction and maintenance efficiency of the pressure vessel.

Through the application of this pressure vessel design system, product design efficiency and quality are greatly improved. All the calculation, design and output data is shown in 3D models, which avoid a repeat data input and ensure the data unification. With automatic engineering drawings and data statistics, the work efficiency of drawings and statistics can be improved more than $80 \%$, and the efficiency can be also improved $50 \%$ at least considering drawing modification work. In addition, the drawings are extremely standard, and the view location and projection angle between different drawings are exactly the same. So there is no need to repeatedly check the drawing quality, and the efficiency of proofreading and checking is also raised.

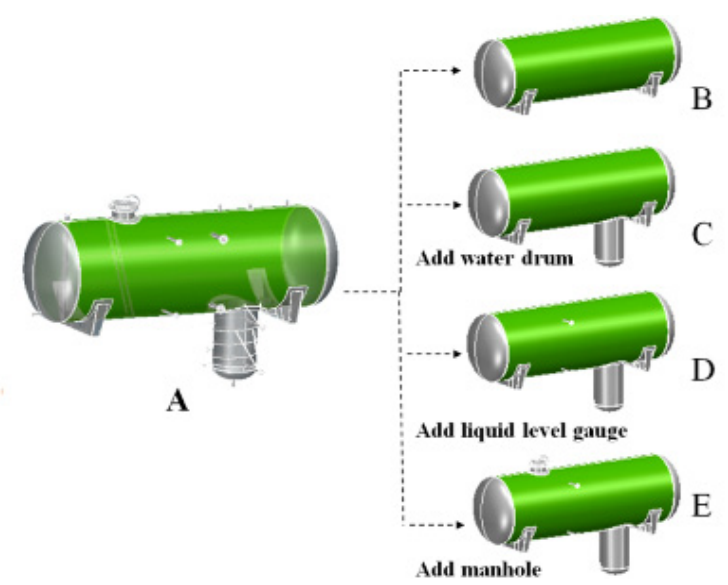

Figure 7. An example of a simple horizontal pressure vessel design

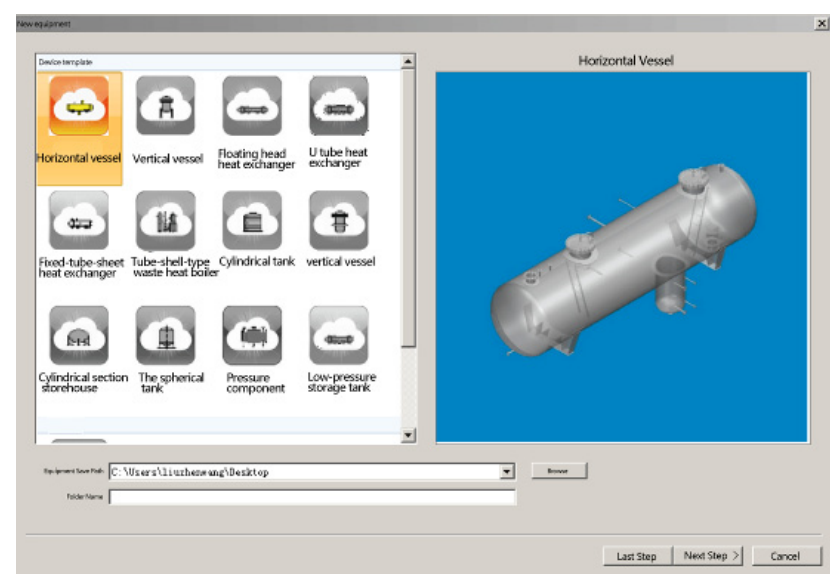

Figure 8. Select "horizontal pressure vessel" design guide

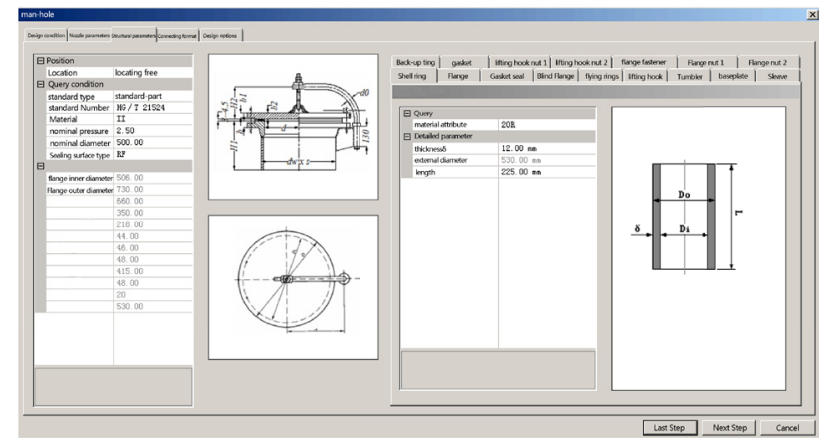

Figure 9. Structure parameters in manhole design guide

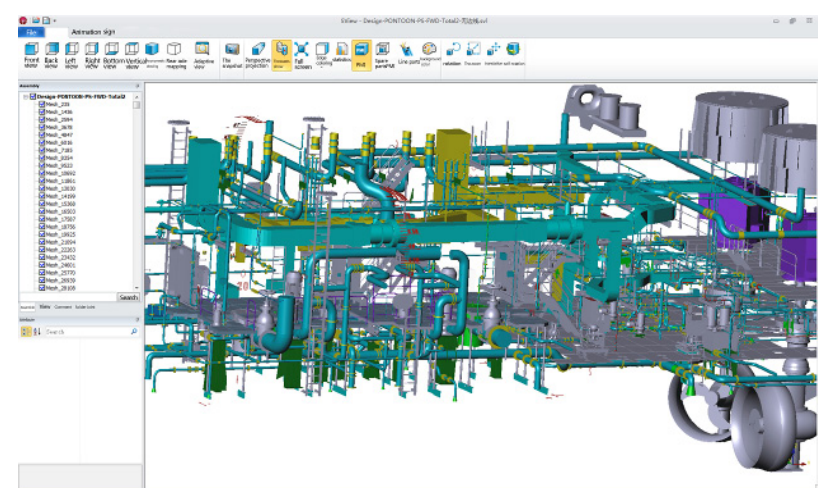

Figure 10. Browse online petrochemical equipment models with mobile devices 


\section{CONCLUSIONS}

The design of pressure vessels has become vitally important for engineers to meet the increasing service demands, quality requirements and safety legislation. In order to provide a convenient and professional design tool to engineers, a guiding design system for pressure vessels based on a domestic 3D CAD system SINOVATION is constructed and implemented. An example of horizontal pressure vessels is presented to verify the efficiency and quality. The main conclusions of this paper are presented below.

(1) In pressure vessel industry, general parts library and standard parts library are required for designers to reduce repeated work and corresponding intensity. It can summarize the characteristics of similar parts, and integrate design experience and formula with $3 \mathrm{D}$ models.

(2) The design guide is presented for typical vessels and components, and a professional design and assembly module is included. This method can guide the designer to finish work step by step, even if there is no design experience. At the same time, it also can provide accurate positioning for product design and assembly.

(3) An example of horizontal pressure vessels is presented. According to the statistics, the work efficiency of drawings and reports can be improved more than $80 \%$, and the efficiency can be also improved $50 \%$ at least considering drawing modification work.

Overall, It is approved that several benefits can be achieved by the use of this system. Such as, product design efficiency and quality are greatly improved, data accuracy and unification are ensured, and proofreading and checking work are reduced with automatic engineering drawings and data statistics. The system is very helpful to design pressure vessels. Next, we will make up for the limitations of CAE analysis, and integrate CAE process into the design guide, but not only input analysis results.

\section{ACKNOWLEDGMENT}

The authors are grateful for the support provided by the Electronic Information Technology Development Foundation of Ministry of Industry and Information Technology.

\section{REFERENCES}

[1] Spence J., A. S. Tooth, and C. W. Bert, "Pressure vessel design: concepts and principles," Journal of Applied Mechanics, vol.62, no.3, pp.824, 1995. http://dx.doi.org/10.1115/1.2897026

[2] Domański J. and Żywica G., "Optimization of the construction of a pressure tank using CAD/CAE systems," Technical Sciences, no. 10 , pp.41-85, 2007.

[3] Thakkar B. S. and Thakkar S. A., "Design of pressure vessel using ASME code, section VIII, division 1," International Journal of Advanced Engineering Research and Studies, no.1, pp.228-234, 2012.

[4] Moss D. R., Basic M., Pressure Vessel Design Manual. Amsterdam: Elsevier, 2013.

[5] Bodein Y. and Rose B. and Caillaud E., "Decisional model for KBE implementation in a commercial CAD software," ComputerAided Design \& Applications, vol.9, no.2, pp.121-131, 2013. http://dx.doi.org/10.3722/cadaps.2012.121-131
[6] Towler G. P. and Sinnott R. K., Chemical Engineering Design: Principles, Practice, and Economics of Plant and Process Design. Oxford, UK: Butterworth-Heinemann Elsevier, 2012.

[7] Bjärkby E., Parameterized Model for Stress Analysis of Nozzles. Chalmers University of Technology, 2011.

[8] Sato T., Nomoto T., Kado K., et al, "Development of user-friendly structural design system for pressure vessels," Transactions of the Japan Society of Mechanical Engineers A, vol.39, no.3, pp.354$361,1996$.

[9] H. J. Aziz, Design Support System for Pressure Vessel Design. Universiti Teknologi PETRONAS, 2014.

[10] Zhu M. S., Long W., Yin L. I., "Development of system for parameterized design and defects assessment of pressure vessels," Manufacture Information Engineering of China, vol.36, no.15, pp.28-31, 2007.

[11] Yun N., Zheng Y. P., Sheng J. S., "Parameterized design of pressure vessels based on AutoCAD," Journal of Jinhua College of Profession \& Technology, vol.7, no.6, pp. 33-34,48, 2007.

[12] I. J. S. Attwater, J. Anderson, G. E. Findlay, “An expert system application combining disparate software to form an integrated pressure vessel design system," Applications of Artificial Intelligence in Engineering VIII, vol.2, pp.161-173, 1993.

[13] Song Y. D., "Design research on pressure vessel of automobiles assembly shop," Applied Mechanics \& Materials, vol.508, pp.204207, 2014. http://dx.doi.org/10.4028/www.scientific.net/AMM. $\underline{508.204}$

[14] Yang X. Q. and Wei J. X., "Mechanical creation design based on 3D CAD," Computer-Aided Industrial Design \& Conceptual Design, 2009. IEEE 10th International Conference on IEEE, pp: 695697, November 2009.

[15] Zhang G., Zhang L. S., Yang S. L. and Zhang L. X., "VB-based AutoCAD for developing commonly-used standard parts library of $3 \mathrm{D}$ chemical equipments," Control and Instruments in Chemical Industry, vol.39, pp.653-655, 2012.

[16] Ellenberger J. P., Chuse R. and Carson B. E., Pressure Vessels: The ASME Code Simplified. New York: McGraw-Hill, 2004.

[17] Chen X., Cui J., Fan Z., et al, "Design, manufacture and maintenance of high-parameter pressure vessels in China," American Society of Mechanical Engineers Pressure Vessels \& Piping Division Pvp, vol.1, pp.V001T01A082, 2014. http://dx.doi.org/10.1115/ pvp2014-28569

[18] Annaratone D., Pressure Vessel Design. Heidelberg: Springer, 2007. http://dx.doi.org/10.1007/978-3-540-49144-6

[19] Zhang Z. F., "Application of PDMS software in high-pressure polyethylene plant," Chemical Engineering Design Communications, vol.33, pp.43-45, 2007.

\section{AUTHORS}

Shanhui Zhang is a lecturer of school of control science and engineering at Shandong University. She received her PhD from Shandong University in 2008. Her research interests lie in the areas of computer-aided design, computer-aided manufacturing, and artificial intelligence (e-mail: happy7054@163.com).

Chaoying Yang was with Shandong University, Jinan, 250061 China. He is now with Shandong Shanda Hoteam Soft Co., Ltd, Jinan, 250101 China (e-mail: ycy@hoteamsoft.com).

Ning $\mathrm{Xu}$ is with Shandong Shanda Hoteam Soft Co., Ltd, Jinan, 250101 China (e-mail: xn@hoteamsoft.com).

Submitted 04 April 2016. Published as resubmitted by the authors 03 May 2016. 